staff of Boghall Experimental Farm. For two years he obtained commercial experience with a well-known firm of Scottish seedsmen. During the War he served in the Middle East and Mediterranean countries, and was appointed deputy assistant director of supplies with executive and advisory responsibilities connected with the production, purchase, storage and distribution of agricultural commodities and the administration of extensive War Department farms in Palestine and Syria. In $1946 \mathrm{Mr}$. Lawrie returned to Britain and joined the Department of Agriculture for Scotland, where he has served for the past nine years.

\section{Use of Radioactive Cæsium for Cancer Treatment}

THE United Kingdom Atomic Energy Authority announces that a new kind of teletherapy source for treatment of deep-seated cancer is being made avail able for use at the Royal Marsden Hospital, London. The principles of such treatment are not new, but this is the first time that radioactive cæsium recovered from 'waste' fission products has been used for this purpose. The source itself is a cæsium salt enclosed in a metal cylinder about one inch in diameter and three inches long. It has an activity of 1,000 curies (equivalent to that produced by a thousand grams of radium). The extraction, refinement and preparation of the source in its capsule was undertaken for the Industrial Group by the Research and Development Branch at the Atomic Energy Factory at Windscale, since the raw materials are stored there. The process is remotely operated within cells having concrete walls several feet thick, and the salt is finally melted at a red heat into the metal capsule. The initial rate of production of these sources will be one to two a month. With the exception of a single experimental source made in the United States, no other country is making cesium on this scale. The suggestion for utilizing radioactive cæsium, which has a useful life of some scores of years, from atomic pile 'waste' arose about 1952 at Harwell, and the Isotope Division there suggested that it might be suitable for cancer therapy. The general proposal to make these sources was announced at a Hospital Physicists' Association meeting in London in 'November 1954, and the first hospitals to use the sources will be the Royal Marsden and Royal South Hants. These hospitals have each designed their own special therapy head to contain the sources; other hospitals may use a head designed by the Isotope Division at Harwell to suit the exsium sources. Two of these heads were exhibited at the International Conference on the Peaceful Uses of Atomic Energy at Geneva.

\section{Science Museum Collection: Supervoltage Machines for X-Ray Therapy}

THE Science Museum, London, has recently gathered together in its Atomic Physics Collection a small group of exhibits relating to linear electronaccelerators. Although for purely research purposes the cyclic accelerators such as the betatron and synchrotron are the most widely used for the production of penetrating $X$-rays for hospital radiotherapy, the travelling-wave linear electron-accelerator has great advantages and is being installed in an increasing number of hospitals in Great Britain. The Science Museum exhibits comprise sectioned parts of an actual accelerator, presented by Mullard, Ltd.; a most ingenious mechanical model illustrating the principle of the travelling-wave accelerator, lent by the Metropolitan-Vickers Electrical Co.,
Ltd.; several diagrams showing the construction and operation of these accelerators; and a group of photographs showing them in use in the Hammersmith Hospital, London, and in the Megavolt Treatment Unit at Newcastle upon Tyne. Other exhibits in this field recently placed on view in the Museum are a betatron presented by the Clarendon Laboratory, Oxford, a model of the Philips cascade generator at the Cavendish Laboratory, Cambridge, and a mechanical model illustrating its principle lent by the Westinghouse Brake and Signal Co.

\section{Rockefeller Grant for Genetics Research at Univer- sity College, London}

THE Rockefeller Foundation has made a grant of 30,000 dollars to the Galton Laboratory of University College, London, for furthering research in genetics, this grant being an extension of a similar one which has been given to the Laboratory since 1946. The work at the Galton Laboratory is exclusively concerned with human genetics, particular attention being paid to certain specific aspects. In the identification of the effects of genes in homozygous and heterozygous form by biochemical methods, precise techniques are being developed which enable the presence or absence of a gene to be established with minimal chance of error ; these principles are being successfully applied to the urinary excretion of cystine and of $\beta$-amino-iso-butyric acid. Work on the gradurl extension of knowledge concerning the human chromosome map is concerned with pairs of conditions located on the same chromosome, which have recently been discovered by members of the staff ; examples are, first, the linkage between elliptocytosis and the $R h$ locus and, secondly, that between the 'nail-patella' syndrome and the $A B O$ locus. For the ascertainment of the part played by genes in morphological and metrical traits, both normal and abnormal, noticeable at birth, special attention is being paid to fotal malformations of specific types, including mongolism; the genetical contribution of the mother to weight of the child at birth is being confirmed. Finally, existing methods, and new ones, are being applied to the statistical and mathematical analysis of human genetical data, special attention being paid to the precise ascertainment of gene frequencies and the exact measurement of linkages.

\section{Photobiology Group}

A Рнотовiology Group has been recently established in Great Britain "for the purpose of bringing together biologists, chemists and physicists with an interest in this field, to further scientific discussion in this country and to explore the possibilities of international co-operation". The members of the organizing committee are: Chairman, Dr. M. H. Pirenne; Vice-Chairman, Prof. J. A. V. Butler; Secretary, Dr. Edna M. F. Roe ; with Dr. Ph. Bauwens, Dr. E. J. Bowen, Dr. R. Hill, Dr. A. D. Lees and Dr. N. Uri. The first meeting of the Group will be held on October 3, 10 a.m.-6 p.m., at Bedford College, Regents Park, London, N.W.1, when four papers will be read : light absorption and energy transfer (Dr. E. J. Bowen); the present state of photosynthesis research (Dr. R. Hill); photosensitive pigment in the retina (Dr. W. A. H. Rushton); and basic principles in the measurement of light energy (J. S. Preston). Those wishing to attend the meeting should write before September 19 to Dr. Edna M. F. Roe, Chester Beatty Research Institute, 